\title{
Conflicto y libertad en la teoría política de Nicolás Maquiavelo y John Stuart Mill
}

\author{
María POLLiTZer \\ Universidad Católica Argentina \\ maria_pollitzer@hotmail.com
}

Recibido: 12 de septiembre de 2014

Aceptado: 1 de enero de 2015

\section{RESUMEN}

Preocupado por la preservación de la libertad en las repúblicas, Maquiavelo es uno de los primeros pensadores modernos en rescatar el carácter positivo que esconden, potencialmente, el tumulto social y los conflictos internos a la hora de fundar el vivere libero. Tres siglos después, interpelado por un nuevo tipo de malestar, Mill reconoce en el antagonismo sistemático la principal herramienta para reconciliar estabilidad y progreso y garantizar el desarrollo de la libertad en el seno de las sociedades democráticas. El objeto del siguiente trabajo es revisitar la manera en la que ambos pensadores teorizaron el conflicto a los fines de precisar la vinculación que este guarda con la libertad. Nos anima el propósito de examinar, entonces, la naturaleza y los límites del antagonismo que reivindican, los ámbitos en los que puede y/o debe encauzarse y los efectos que ambos le atribuyen.

\section{PALABRAS CLAVE}

Nicolás Maquiavelo, John Stuart Mill, conflicto, libertad, república.

\section{Conflict and Liberty in the Political Theory of Niccolò Machiavelli and John Stuart Mill}

\begin{abstract}
In conjuction with his concern for preserving liberties in Republics, Machiavelli is known as one of the first modern political thinkers to point out the benefits derived from social unrest and internal conflicts in any society that seeks the vivere libero. Three centuries later and in a context of very different concerns, Mill presented systematic antagonism as the main device by which stability and progress can be reconciled and freedom can be ensured within democratic societies. This article examines the way in which both thinkers theorized the nature of conflict, its limits as well as its effects, and finally, the areas in which they can or should be channeled.
\end{abstract}

\section{KEY WORDS}

Machiavelli, John Stuart Mill, conflict, freedom, republic. 


\section{INTRODUCCIÓN}

Interpelado, entre otras cosas, por el desafío que supone establecer y conservar la libertad, Nicolás Maquiavelo (1469-1527) es el primero en rescatar el carácter positivo que esconden, potencialmente, el tumulto social y los conflictos internos a la hora de fundar el vivere politico. John Greville Agard Pocock, Quentin Skinner y Maurizio Viroli ${ }^{1}$ han subrayado ya el carácter novedoso, audaz y hasta desconcertante de esta tesis, por cuanto resulta un distanciamiento de la prédica del humanismo cívico y de la tradición republicana en general, que hacía de la visión ciceroniana de la concordia ordinum el cemento indispensable sobre el cual podía edificarse un régimen que aspirase a dar cabida a la libertad. ¿Cómo opera este cambio de perspectiva? ¿Cuáles son los argumentos con los que Maquiavelo transforma el conflicto de enemigo a garante principal de la libertad? Para responder estos interrogantes es preciso adentrarse en el análisis que el florentino presenta en dos de sus obras más conocidas: Discursos sobre la primera década de Tito Livio y su Historia de Florencia. Un análisis que se despliega sobre un doble juego de comparaciones, entre la Roma republicana y los modelos de Esparta y Venecia, por un lado, y entre aquella y el caso de Florencia, por el otro. Es en el saldo de esta aproximación comparativa en donde se encuentran las claves de lectura que permiten desentrañar cuál es, para Maquiavelo, el origen de los conflictos en las sociedades humanas; cuáles, los objetivos que persiguen las partes en pugna y sus diferentes efectos; qué importancia adquieren los medios a través de los cuáles estos se canalizan; y finalmente, su vinculación con la virtù y la libertad. Todos ellos, elementos necesarios para explicar la inversión valorativa a la que se hacía referencia. Sobre estos aspectos versa, entonces, la primera parte del trabajo.

Ahora bien, la intención que anima este escrito no se restringe al análisis de las observaciones, poco sistemáticas aunque originales, ofrecidas por Maquiavelo sobre la inevitabilidad y virtualidad positiva del antagonismo. Me interesa, también, trazar una línea de continuidad entre dichas reflexiones y la manera en la que, trescientos años después, y desde un contexto histórico y discursivo distinto, John Stuart Mill (1806-1873) teorizó el tema del conflicto. En efecto, para el utilitarista inglés, la existencia del antagonismo resulta saludable y fecunda

${ }^{1}$ John Greville Agard Pocock, El momento maquiavélico. El pensamiento florentino y la tradición republicana atlántica, Tecnos, Madrid, 2000, p. 277; y Gisela BocK, Quentin SKINNER, y Maurizio VIroli (eds.), Machiavelli and Republicanism, Cambridge University Press, Cambridge, 1990, pp. 136, 157. 
"en todos los asuntos humanos"2. Antes que sortearlo, Mill se propuso integrar el conflicto como un elemento necesario e indispensable tanto para el crecimiento individual como para el progreso de una sociedad libre. En este sentido, por debajo de las propuestas concretas que alentó a lo largo de su vida en los más diversos ámbitos subyace, cual denominador común, la firme convicción respecto de la vinculación inescindible entre la libertad y la existencia de antagonismos. Reconstruir el argumento que sirve de fundamento a dicha vinculación es el objeto de la segunda parte del artículo. En él se analizan también los escenarios en los que Mill cree conveniente rehabilitar el antagonismo y qué tipo de estrategias propone. Este tipo de análisis requiere una lectura transversal del conjunto de su producción escrita, en tanto y en cuanto se trata de una preocupación que lo acompañó a lo largo de toda su vida, pero para la cual no destinó de manera directa o exclusiva ningún trabajo.

Una vez presentadas ambas lecturas, la tercera y última parte está destinada a poner de relieve - a modo de conclusión - los ecos maquiavélicos presentes en la obra del pensador inglés, un área poco explorada en el conjunto de la vasta producción académica que se ocupa de la obra de Mill. Muchos han analizado las diversas fuentes intelectuales que nutrieron su pensamiento: el radicalismo benthamista, el primer socialismo, el romanticismo, el liberalismo continental e, incluso, el mundo griego. En las últimas décadas, algunos se han embarcado en una relectura de su obra en clave republicana. Tal es el caso de Eldon Eisenach, Dale Miller, Nadia Urbinati o Alex Zakaras, quienes han rescatado la dimensión cívica de su liberalismo ${ }^{3}$. En parte, es en esta senda que se inscribe el presente trabajo. Si bien es cierto que el florentino no figura entre los grandes nombres que jalonan la Autobiografía de Mill, y que son escasas las referencias directas que aparecen en su obra hacia su persona o sus ideas, no caben dudas de que Mill leyó al menos los Discursos, El Príncipe y la Historia de Florencia, y que mantuvo contacto con quien fuera uno de los biógrafos más reconocidos de Maquiavelo en el siglo diecinueve, Pasquale Villari (1827-

2 John Stuart MiLl, "Considerations on Representative Government" (1861), en Collected Works of John Stuart Mill, 33 vols., ed. de J. M. Robson, University of Toronto Press, Toronto, 1977, vol. XIX, Essays on Politics and Society Part 2, p. 439.

${ }^{3}$ Eldon J. EISENACH, "Self-Reform as Political Reform in the Writings of John Stuart Mill": Utilitas, vol. I, n. ${ }^{\circ} 2$ (1998), pp. 242-258; Dale Miller, "J. S. Mill's Civic Liberalism": History of Political Thought, vol. XXI, n. ${ }^{\circ}$ (2000), pp. 88-113; Nadia Urbinati, Mill on Democracy. From the Athenian Polis to Representative Government, Chicago University Press, Chicago \& London, 2002 y Alex ZaKaras, "J. S. Mill, Individuality and Participatory Democracy", en Nadia URBINATI y Alex Zakaras (eds.), John Stuart Mill's Political Thought. A Bicentennial Reassessment, Cambridge University Press, Cambridge, New York, 2007, pp. 200-220. 
$1917)^{4}$. En cualquier caso, ponerlos a dialogar permite analizar los puntos de contacto y de divergencia en la manera en que ambos entendieron el vínculo que une la libertad con el antagonismo, entendido aquí en sentido amplio, como sinónimo de conflicto.

\section{"INCONVENIENTES NECESARIOS": ORIGEN Y EFECTOS DE LOS CONFLICTOS SOCIA- LeS SEGÚN MAQUiAVElo}

El análisis que Maquiavelo ofrece sobre los conflictos y su relación con el vivere libero presenta, inicialmente, dos limitaciones. Una guarda relación con su condición de teórico de la política no sistemático, es decir, con el hecho de enfrentarnos a un pensador que no siempre cierra sus argumentos de manera conclusiva o acaso se preocupa por explicitar sus últimas consecuencias. Antes bien, en varias ocasiones las premisas se van superponiendo y el autor deja que las diferentes aristas que un tema admite se vayan presentando al lector sin preocuparse por el carácter abierto que revisten sus razonamientos. No siempre es preciso con los conceptos que utiliza y sus referencias históricas, por momentos, son antojadizas o un tanto inexactas. La otra tiene que ver con el lugar que ocupa este tema en el conjunto de su reflexión. Es importante recordar que la cuestión del conflicto no es en sí misma una idea central para el florentino, sino que se encuentra subordinada a las ideas ejes de la libertad, la virtù y el poder. No encontraremos en su obra un tratamiento detenido ni exhaustivo que dé cuenta de los distintos tipos de conflictos que pueden aparecer en las sociedades, ni de los diversos ámbitos en los que puede encarnarse. No le interesa tampoco hacer un juicio moral sobre los mismos, ni sobre los canales por medio de los cuales se expresa. Su mirada es eminentemente pragmática y política y su interés en este campo es señalar la manera más conveniente en que la política puede lidiar con aquello que constituye un dato más de la realidad. Atendiendo a estas observaciones, en los párrafos que siguen se presenta una síntesis de sus principales contribuciones en esta materia.

${ }^{4}$ A modo de ejemplo, ver: John Stuart MiLl, "The British Constitution”, en Collected Works, vol. XXVI, Journals and Debating Speeches Part I, p. 369; y “Taylor's Statesman”, en Collected Works, vol. XIX, Essays on Politics and Society, Part 2, pp. 624-625. Existen registros de al menos veinte cartas enviadas por Mill a Villari entre 1854 y 1872. 


\section{Humores contrapuestos y desunión}

En línea con la consigna que guía su reflexión, aquella que fuerza a concentrar la mirada en "la verdad real de la materia (verità effetuale)", antes que "en los desvaríos de la imaginación"s, Maquiavelo parte del reconocimiento de la naturalidad y lo inexorable de los conflictos en todas las sociedades humanas. Estos tienen su origen en la existencia de dos humores contrapuestos en el seno de toda ciudad, identificable uno, con los nobles o los grandes, y el otro, con el pueblo o el popolo. El de los primeros se caracteriza por "el deseo de dominar", mientras que el de los segundos, por el "deseo de no ser dominados"6. Tras esta inclinación principal se cuelan la ambición, el temor a perder lo adquirido y la soberbia, en el caso de los grandes y el ánimo inquieto y el deseo de obtener nuevos honores y riquezas, en el caso del pueblo. Unos cuentan con mayor poder y operatividad, mientras que los otros anhelan ante todo vivir libres y conforme a las leyes?.

Como puede observarse, estos humores orientan la conducta política de ambos grupos y los conducen inevitablemente al enfrentamiento, son el origen de las disputas y los tumultos que la historia ha venido registrando a lo largo de los siglos ${ }^{8}$. Tal como constata Ernesto Funes, Maquiavelo está convencido de que "la ciudad no es una unidad sino una multiplicidad (no es un uno, es un dos), y ese dos no es armónico, sino conflictivo". Ello lo fuerza a mitigar su elogio del modelo espartano y veneciano, ejemplos de repúblicas que buscaron establecer la unidad y se vieron exentas de los tumultos por mucho tiempo.

Su argumento se despliega a lo largo de los primeros capítulos del libro I de los Discursos. Allí, Esparta es presentada como una república con un ordenamiento institucional producto de la previsión de un sabio legislador, quien supo limitar y distribuir el poder entre los reyes, los nobles y el pueblo. Pocos gober-

${ }^{5}$ Nicolás Maquiavelo, El Príncipe, Espasa Calpe, Madrid, 1961, p. 76.

${ }^{6}$ En el capítulo I del libro III de la Historia de Florencia, Maquiavelo se refiere a esta dupla de humores con otros términos, que no son sus exactos equivalentes: "Las graves y naturales enemistades que existen entre plebeyos y nobles, por querer éstos mandar y aquéllos no obedecer...". MaQuiaVelo, "Historia de Florencia", en Obras históricas de Nicolás Maquiavelo, Poseidón, Buenos Aires, 1943, pp. 144-145.

${ }^{7}$ Nicolás MaquiaVelo, Discursos sobre la primera década de Tito Livio, Alianza Editorial, Madrid, 1996, Libro I, cap. 5, pp. 41-43 e "Historia de Florencia", Libro I, cap. 11, p. 98 y Libro II, cap. 38, p. 137.

${ }^{8}$ Maquiavelo, Discursos sobre la primera década de Tito Livio, I, 39, p. 127.

${ }^{9}$ Ernesto FunEs, La Desunión. República y no-dominación en Maquiavelo, Editorial Gorla, Buenos Aires, 2004, p. 25. 
naban, manteniéndose alejados del resto, entre quienes no se despertaba el deseo de acceder al poder. La prohibición de ingreso a los extranjeros jugó aquí un rol fundamental, en tanto que mantuvo bajo el número de habitantes y los protegió de dos escenarios problemáticos: la corrupción de sus costumbres y un crecimiento de la ciudad para el cual sus instituciones no estaban preparadas ${ }^{10}$. Estas previsiones aseguraron a Esparta una larga vida en libertad y quietud. La versión moderna de una república libre de conflictos internos es Venecia, que no contó con un Licurgo ni cerró sus puertas a los extranjeros. Pero una vez que la comunidad creció lo suficiente, sus habitantes optaron por bloquear el acceso al gobierno a todos aquellos que se incorporasen a futuro. Como estos tampoco fueron muy numerosos, la desproporción entre gobernantes y gobernados no fue muy grande. La decisión de los patricios de retener para sí el ejercicio de las armas contribuyó también a que no se generaran las condiciones para que el pueblo alterara el orden público. Por último, se nos recuerda que ambas repúblicas confiaron a los nobles la custodia de la libertad y buscaron ante todo "conservarse en su estado" y "mantenerse dentro de estrechos límites"11.

¿Cuáles son, pues, los puntos débiles de estos ejemplos, aquellos que lo inclinan a considerar la superioridad del modelo romano? Básicamente dos: en primer lugar, ni Esparta ni Venecia pueden ser consideradas, en sentido estricto, repúblicas perfectas. Son, más bien, repúblicas aristocráticas que priorizan la unión antes que la desunión. En segundo lugar, sus ordenamientos institucionales descansan en una aspiración que resulta errada o, al menos, ilusoria: la pretensión de mantener el equilibrio indefinidamente o permanecer en el justo medio gozando de una vida pacífica y estable. Detengámonos brevemente a explicar estas objeciones.

Si bien en un primer momento Maquiavelo incluye a Esparta dentro de los regímenes que habían logrado evitar la corrupción inherente a las formas puras, por cuanto en ella el poder quedaba distribuido y mezclado entre el rey, los nobles y el pueblo, lo cierto es que, avanzado el argumento, el elemento popular es dejado de lado y solo se señala que en ella gobernaba "un rey y un pequeño senado" ${ }^{12}$. En el caso de Venecia, se reconoce explícitamente que ella "no ha dividido el gobierno verbalmente, sino que todos los que pueden encargarse de la administración se unen bajo el apelativo de patricios"13. En ambos ejemplos,

\footnotetext{
${ }^{10}$ Maquiavelo, Discursos sobre la primera década de Tito Livio, II, 3, pp. 191-192.

${ }^{11}$ Ibid., I, 5, p. 42 y I, 6, p. 46.

${ }^{12}$ Ibid., I, 6, pp. 44-45.

${ }^{13}$ Ibidem.
} 
la conducción política parece haber quedado en manos de un solo grupo y este ordenamiento, recordemos, fue el que evitó los conflictos e hizo posible que sus habitantes vivieran unidos por mucho tiempo. En opinión de Funes, lo que Maquiavelo nos presenta aquí sería una suerte de modelo intermedio entre las formas puras y el régimen mixto, en el que el límite y el control del poder no resultan de la participación de distintos grupos en el gobierno sino, ante todo, de la existencia de controles internos autoimpuestos muy rígidos y de mecanismos que restringen el acceso al poder. Si extremamos el argumento, la pluralidad de la ciudad es reconducida, en este escenario, a una unidad que se presenta como la encarnación de la totalidad. La paz y el orden que se respiran son, así, la moneda de cambio de la subordinación de los muchos a un solo grupo ${ }^{14}$.

En contrapartida, tras la revolución del 509 a. C., Roma construyó un verdadero modelo mixto, por medio del cual supo dar cabida a una multiplicidad de grupos que se vieron impelidos a compartir el poder. A diferencia de las otras repúblicas, ella confió a la plebe la garantía de la libertad, entendiendo que esta se encontraba a mejor resguardo en manos de quienes no tenían deseos de usurparla. Su apuesta fue la desunión, un concepto que no debe ser confundido con el de división o el de conflicto sin más ${ }^{15}$. La desunión es una alternativa política, es una construcción artificial que implica institucionalizar estas divisiones en lugar de anularlas. Consiste en ordenar la ciudad de tal manera que "las alteraciones de humores que la agitan tengan una salida prevista por la ley" ${ }^{\prime 16}$. La creación de los tribunos de la plebe, por ejemplo, sirvió precisamente a estos fines: encauzar políticamente las pasiones del pueblo y contener las pretensiones de los nobles. Desde esta perspectiva, mientras que las repúblicas aristocráticas se revelan como regímenes de dominación de los grandes que se enmascaran bajo el velo legitimador de la unión, la república popular romana, fundada en la desunión y abierta a la participación de la multiplicidad, pone un freno al abuso de poder por parte de alguno de los grupos que integran la ciudad y permite el verdadero vivere libero.

La segunda objeción que coloca a Esparta y a Venecia en inferioridad de condiciones respecto del modelo romano se refiere al modo en que cada una hace frente a los avatares de la fortuna. La contracara de la unión y la quietud de las

${ }^{14}$ Funes, La Desunión, pp. 84, 95-96.

${ }^{15}$ Coincido con el análisis del concepto de desunión que presenta Funes en su texto. Sin embargo, observo que Maquiavelo no es tan cuidadoso con los términos que utiliza y en más de una ocasión el vocablo desunión aparece asociado a la debilidad o confundido con el de mera división. Maquiavelo, Discursos sobre la primera década de Tito Livio, I, 12, p. 70; III, 11, pp. 337338. Maquiavelo, "Historia de Florencia", II, 35, p. 128.

${ }^{16}$ Maquiavelo, Discursos sobre la primera década de Tito Livio, I, 7, p. 49. 
primeras es su debilidad. Al priorizar la conservación de lo adquirido por sobre la posibilidad de la expansión, dichas repúblicas se ven compelidas a mantenerse dentro de sus estrechos límites a fin de evitar lo que constituye "su ruina segu-

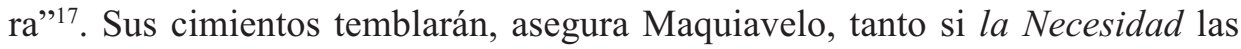
fuerza a extenderse (desafío para el cual sus instituciones no se encuentran preparadas) como si esta las libra de la guerra, escenario en el que florecerán el ocio y el afeminamiento de la vida, gérmenes de la corrupción. Atar la independencia de una ciudad a determinadas condiciones de equilibrio supone desconocer que "todas las cosas de los hombres están siempre en movimiento y no pueden permanecer estables"18. Esparta y Venecia pueden ser consideradas "repúblicas felices", pero no "repúblicas perfectas". Para alcanzar esta perfección es preciso dotar a la ciudad de las herramientas necesarias para hacer frente a los cambios que, inevitablemente, se presentarán. Resulta necesario, por lo tanto, organizarla de tal modo que pueda no solo defenderse, sino expandirse y conservar lo conquistado. Y el reverso de esta aspiración a la grandeza es el empoderamiento del pueblo. Al abrir sus puertas a los extranjeros (a diferencia de Esparta) y al recurrir a la plebe para nutrir las filas del ejército (a diferencia de Venecia), Roma proporcionó a la plebe "fuerza y aumento", con lo que dio cauce al nacimiento de "infinitas ocasiones" en las que se podía alterar el orden público. Pero estos conflictos y tumultos no fueron más que "inconvenientes necesarios"19. Debidamente canalizados, dieron lugar a la "república perfecta", que es aquella que no solo evita la dominación sino que se alza en mejores condiciones para afrontar los embates de la fortuna. En efecto, Maquiavelo sostiene que la república "se adapta mejor a la diversidad de las circunstancias", afirmación que fundamenta en el hecho de que este es el régimen que da cabida a "distintos ciudadanos y distintos modos de ser", lo que le otorga a sus movimientos mayor ductilidad. Las repúblicas perfectas son pues, en palabras de Claudia Hilb, las que "hacen gala de su virtù" y se muestran "más conforme[s] a la naturaleza temporal, cambiante, de la cosa política" ${ }^{20}$.

Recopilando, los conflictos, las discordias y tumultos son naturales y por tanto inevitables en toda sociedad. La política puede suprimirlos o encauzarlos, puede fundar un orden basado en la unión o en la desunión, pero solo la desunión

\footnotetext{
${ }^{17}$ Ibid., I, 6, p. 47.

${ }^{18}$ Ibid., p. 48.

${ }^{19}$ Ibidem.

${ }^{20}$ Claudia HiLb, "Maquiavelo, la república y la virtù", en Tomás VÁRnAGY (comp.), Fortuna y virtud en la república democrática. Ensayos sobre Maquiavelo, CLACSO, Buenos Aires,
} 2000, pp. 137-138. 
es la causa de la libertad. La Roma tumultuosa y desunida es una alternativa superadora de la Esparta o la Venecia tranquila y unida porque su ordenamiento institucional evita la dominación de uno o de un grupo sobre el resto y se halla en mejores condiciones para adecuarse a la dinámica de la fortuna.

\section{Facciones, tiranía y libertad}

Ahora bien, Maquiavelo trabaja en paralelo con otro modelo republicano, el de Florencia, en el que los conflictos y tumultos también están a la orden del día. Sin embargo, en varios pasajes de la Historia de Florencia, estos son reputados como responsables del derramamiento de sangre y del desorden que caracterizan la historia de su ciudad, de las dificultades que encuentra Italia para consolidar su unidad nacional e incluso, de la ruina y caída de la república romana ${ }^{21}$. Parecería que el florentino adjudica efectos contrarios a una misma causa, dificultad que ha sido abordada, entre otros, por Gisela Bock, y que explica la apreciación desigual que sobre este punto ha recibido Maquiavelo entre sus variados lectores. Veamos, entonces, más allá de algunas imprecisiones y lagunas argumentales, qué enseñanzas podemos extraer de la comparación entre los efectos ocasionados por los conflictos en Roma y en Florencia.

En el comienzo del libro III de la Historia de Florencia se nos recuerda que la diversidad de inclinaciones (lo que en los Discursos había llamado humores) es la responsable de las enemistades entre los nobles y los plebeyos, pero - acto seguido- se precisa que este punto de partida que podríamos llamar universal no conduce a un resultado unívoco. En Roma, su efecto fue la desunión (y, consiguientemente, la libertad) mientras que en Florencia, la división (y, por tanto, la ruina del estado). Lo que explica este resultado dispar son tanto los medios utilizados como los fines perseguidos por las partes en pugna. En cuanto a los primeros, Maquiavelo señala que en Roma las enemistades se expresaban por medio de disputas ${ }^{22}$, mientras que en Florencia adoptaban la forma de combate. En los trescientos años que separan la expulsión de los Tarquinos del advenimiento de los Graco, la República romana conoció pocos exilios y pocas ejecuciones, la plebe se valió de procedimientos "normales", establecidos por la ley, para "desfogar sus iras" y no recurrió, como en el caso de los florentinos, ni a las

\footnotetext{
${ }^{21}$ A modo de ejemplo, Maquiavelo, "Historia de Florencia", I, pp. 47,53, 56, 63; Ibid., II, 95, 98; y Maquiavelo, Discursos sobre la primera década de Tito Livio, I, 6, p. 44.

${ }^{22}$ En el capítulo IV de los Discursos las disputas aparecen ejemplificadas como corridas tumultuosas por las calles, saqueos de tiendas o bien, la negativa por parte de la plebe a prestar servicio militar.
} 
fuerzas privadas ni a las extranjeras ${ }^{23}$. El recurso a los medios extraordinarios siempre engendra miedo y odio entre las partes, lo que lleva a la división, y esta a la aparición de facciones, bandos o partidos. Las facciones serían, pues, divisiones artificiales que se manejan por fuera de los cauces legales y procuran su propia utilidad. Mientras que en Florencia el faccionalismo condujo a la muerte de la parte vencida o a su destierro, y las reformas introducidas una vez finalizados los enfrentamientos solo beneficiaron al partido vencedor, las disputas entre los humores romanos concluyeron con la elaboración de leyes con vistas al bien común ${ }^{24}$.

La diferencia de fondo estriba en que, entre los romanos, el pueblo "aspiraba a obtener el poder y desempeñar como los nobles las primeras dignidades, mientras que el de Florencia quería ejercer solo y sin participación de los nobles la gobernación del Estado". Maquiavelo juzga la primera como una aspiración "más razonable" y la segunda como "injuriosa e injusta"25. Al compartir con los nobles la conducción del estado, el pueblo romano "se contagió" de sus "cualidades brillantes" y pudo crecer en virtud y en poder. En contrapartida, cuando vencía el pueblo florentino, "los nobles eran privados de los cargos públicos y, para reconquistarlos, necesitaban asimilarse, no sólo en la apariencia, sino en la realidad, a las opiniones, costumbres y modo de vivir del pueblo"26. Como resultado, el valor militar y la generosidad de sentimientos se extinguían entre los nobles y Florencia se volvía cada vez más humilde y abyecta.

Es claro que para Maquiavelo su ciudad natal carecía de un ordenamiento político adecuado. A lo largo de su historia, los florentinos habían errado los sucesivos diseños institucionales al no dar cabida a todos los elementos de la sociedad. Admite así, que cuando las ciudades no están bien ordenadas oscilan entre la servidumbre y la licencia. En una los nobles y en otra los demagogos gobiernan sin respetar la libertad y sin obedecer las leyes. "En uno tienen sobrada autoridad los insolentes, en el otro los ignorantes"27. Es por ello que, en el dictamen sobre la reforma de la constitución de Florencia hecho a instancias del Papa León X, Maquiavelo se permite advertir a quienes se propongan establecer una república que han de hacer intervenir en su gobierno "a las tres clases de

${ }^{23}$ Maquiavelo, Discursos sobre la primera década de Tito Livio, I, 4, p. 39.

${ }^{24}$ Maquiavelo, "Historia de Florencia", VII, 1, p. 340.

${ }^{25}$ Ibid., III, 1, pp. 144-145. La constatación del comportamiento desigual que mostró el pueblo en Roma y en Florencia plantea un interrogante respecto de la apreciación que tantas veces hace el florentino sobre la regularidad de la conducta humana.

${ }^{26}$ Ibid., III, 1, p. 145.

${ }^{27}$ Ibid., IV, 1, p. 192. 
hombres que forman la ciudad: los principales, los medianos y los últimos"28. En otras palabras, si se quiere evitar la dominación tanto de parte de los nobles como del pueblo, es preciso establecer un régimen mixto, un régimen que institucionalice los humores contrapuestos de la ciudad y los disuada de recurrir a medios excepcionales, aquellos que dan origen a las facciones y hacen que los conflictos terminen cercenando la libertad.

Por último, la comparación entre Roma y Florencia y el modo en que ambas procesaron los tumultos arroja dos enseñanzas más. Una nos recuerda las limitaciones con las que se encuentra el orden político para mantener encauzados los humores sociales y evitar los efectos nocivos asociados a la aparición de facciones, y la otra nos invita a considerar la relación entre un contexto de corrupción y el rol que en él le cabe a los conflictos. En efecto, Maquiavelo afirma - sin dar mayores precisiones - que las graves enemistades entre nobles y plebeyos terminaron conduciendo en última instancia a un escenario de desigualdad entre los romanos y a uno de completa igualdad entre los florentinos. De manera que la república "perfecta" fue presa de la corrupción y terminó sucumbiendo bajo la tiranía: "Convertida la virtud de la nobleza romana en orgullo llegó a términos que, sin un príncipe, no se podía conservar el Estado"29. Por su parte, la dividida y desordenada Florencia es presentada como materia dispuesta para ser reformada por un "sabio legislador" quien, según sugiere al papa León X en el dictamen mencionado, debería pensar en una forma republicana antes que en una monárquica $^{30}$.

Frente a estos pasajes cabe preguntarse cómo es posible que aquella que encauzó sus conflictos disputando civilmente termine perdiendo su libertad y que la que, por el contrario, no supo o no pudo canalizarlos adecuadamente se encuentre tan próxima a la república. Como primera respuesta, nuestro autor recuerda en los Discursos que "es imposible organizar una república perpetua, pues su ruina puede producirse por mil motivos inesperados"31. Y el saldo de esta comparación vuelve evidente, a sus ojos, el hecho de que los actores sociales no son capaces de dominar por completo los resultados de la acción política ${ }^{32}$. En

\footnotetext{
${ }^{28}$ Maquiavelo, "Dictamen sobre la reforma de la Constitución de Florencia hecho a instancias del Papa León X", en Obras históricas de Nicolás Maquiavelo, Poseidón, Buenos Aires, 1943 , p. 571.

${ }^{29}$ Maquiavelo, "Historia de Florencia", III, 1, pp. 144-145.

${ }^{30}$ Maquiavelo, "Dictamen sobre la reforma de la Constitución de Florencia hecho a instancias del Papa León X”, p. 570.

${ }^{31}$ Maquiavelo, Discursos sobre la primera década de Tito Livio, III, 17, p. 354.

${ }^{32}$ Miguel SARAlEgUI, "Maquiavelo y la partidocracia: tumulto social y mantenimiento de la libertad": Anuario Filosófico, vol. XL, n. ${ }^{\circ} 1$ (2007), p. 216.
} 
este caso puntual de Roma, Maquiavelo señala dos razones que explican la disolución de la república: las consecuencias no intencionadas (si es que cabe la expresión) que trajo aparejada la puesta en discusión de la adormecida ley agraria por parte de los Graco y la prórroga de los mandos militares. No se interesa Maquiavelo por la bondad o la validez de dicha ley, ni acaso por las intenciones detrás del accionar de los Graco. Su atención recae sobre los efectos que produjo:

Encendió tanto odio entre la plebe y el senado que se llegó a las armas y a la sangre, fuera de todo orden civil. De modo que, no pudiendo controlar la situación los magistrados públicos, y sin que ninguna de las facciones esperara que lo hicieran, se recurrió a procedimientos privados y cada parte procuró buscar un jefe que la defendiese ${ }^{33}$.

$\mathrm{Al}$ deseo de no ser dominados (pasión dominante entre los plebeyos) se sumó la ambición por disfrutar de las riquezas de los nobles, quienes se obstinaron en defender sus bienes con mucho mayor recelo del que habían manifestado a la hora de compartir los honores. El odio envileció las relaciones entre ambos grupos y el orden político se mostró incapaz de contener o resolver los nuevos conflictos dentro de los cauces legales. Paralelamente, gracias a la prórroga de las magistraturas, y luego, de los mandos militares, el número de ciudadanos capaces de adquirir reputación por estos medios se redujo considerablemente y el vínculo de amistad y obediencia que se establecía entre el ejército y su conductor en tan largos períodos hizo que el ejército no reconociera ya la autoridad del senado sino únicamente la de aquel ${ }^{34}$. Sila, Mario, Pompeyo y César, cada uno liderando las facciones enfrentadas, jalonaron el camino que llevó de la guerra civil a la tiranía.

Este proceso de corrupción abarcó varias generaciones, lapso durante el cual la república no fue "renovada a menudo [ni] retraída a sus principios con los buenos ejemplos y las buenas leyes"35. Sucede que el orden político es un frágil artificio que necesita ser "vivificado" por la actuación recurrente y no muy espaciada de hombres destacados por su virtud, quienes con su ejemplo y su accionar recuerden al resto de los ciudadanos los principios que sostienen a la república. Cuando estos escasean, no hay nada que detenga la corrupción de las costumbres

\footnotetext{
${ }^{33}$ Maquiavelo, Discursos sobre la primera década de Tito Livio, I, 37, p. 122. La cursiva es mía.

${ }^{34}$ Ibid., III, 24, pp. 370-371.

${ }^{35}$ Ibid., III, 8, p. 329.
} 
ni la trasgresión de las leyes ${ }^{36}$. La virtù de la república necesita, como vemos, de la virtud de los ciudadanos.

Aparición de facciones y escasez de hombres virtuosos son señales del crecimiento de la desigualdad. De hecho, Maquiavelo sentencia que "la corrupción y la falta de aptitud para la vida libre nacen de la desigualdad" 37 , concepto cuyo significado exacto no explicita pero que también es señalado en la comparación con el caso florentino como vimos más arriba. Considerando las reflexiones dispersas que se ofrecen sobre el mismo en los Discursos, Pocock sugiere que la desigualdad designa, para Maquiavelo, "una situación en la que algunos hombres dirigen su atención a otros hombres cuando deberían dirigirla al bien y a la autoridad pública". Inversamente, un escenario de igualdad sería aquel en el que "todos atienden en las mismas condiciones al bien público", lo que implica según esta lógica argumental - que todos los ciudadanos sean hombres independientes, capaces de armarse en defensa de su patria ${ }^{38}$. No fueron entonces los conflictos los causantes de la crisis de la república, sino la aparición de facciones en un contexto de creciente desigualdad. Lo que no queda claro es el proceso por medio del cual Florencia habría arribado a una situación de igualdad. En el dictamen elevado al Papa reitera que en ella reina una igualdad "grandísima" y existen "las mejores condiciones" para establecer una república ${ }^{39}$. ¿Acaso Florencia no se encuentra incluida dentro de la descripción de corrupción general que le cabe a Italia en el famoso capítulo XXVI de El Príncipe? De cualquier manera, si prestamos atención a las aclaraciones que ofrece tras presentar el modelo de constitución que convendría darle a su ciudad tras la muerte de Lorenzo de Médicis (1449-1492), observaremos que el establecimiento de la república tendrá un carácter más bien paulatino.

Sea cual sea su valoración sobre las condiciones existentes en la Florencia del siglo dieciséis, lo cierto es que Maquiavelo no se cansa de repetir que cuando los pueblos están corrompidos "hasta las vísceras" resulta muy difícil mantener o restablecer en su seno la libertad. Para "regenerar la materia" es preciso "recurrir a muchas medidas excepcionales que pocos saben o quieren usar" Habría que recurrir a la violencia y las armas y convocar a un príncipe para que, disponiendo todo a su modo, logre reconducir la ciudad hacia sus verdaderos

\footnotetext{
${ }^{36}$ Ibid., III, 1, pp. 291-292.

${ }^{37}$ Ibid., I, 17, p. 83.

${ }^{38}$ Pocock, El momento maquiavélico, pp. 292-293.

${ }^{39}$ MaquiaVelo, "Dictamen sobre la reforma de la Constitución de Florencia hecho a instancias del Papa León X”, p. 570.

${ }^{40}$ Maquiavelo, Discursos sobre la primera década de Tito Livio, I, 17, p. 83.
} 
principios. Una empresa de cumplimiento improbable, puesto que "reconducir una ciudad a una verdadera vida política presupone un hombre bueno, y volverse, por la violencia, príncipe de una ciudad presupone uno malo"41. Si acaso estos obstáculos se sortearan, Maquiavelo estima que el nuevo orden habría de inclinarse hacia la monarquía, "para que los hombres cuya insolencia no puede ser corregida por las leyes sean frenados de algún modo por una potestad casi regia" ${ }^{42}$. Coincido en este punto con el análisis que propone Hilb, cuando entiende que en este horizonte, si el nuevo príncipe pretende mantener su dominación sin verse confrontado permanentemente a la rebelión "deberá neutralizar...el conflicto entre el pueblo y los grandi: habrá de contener en su persona la división, así como contienen la división las instituciones republicanas en su equilibrio"43.

En conclusión, "cuando la materia no está corrompida, las revueltas y otras alteraciones no [la] perjudican" sino que, por el contrario, la favorecen. Pero cuando lo está, cuando la corrupción ha penetrado por todas partes la ciudad "las leyes bien ordenadas [ya] no la benefician" ${ }^{4}$, la desunión se vuelve ineficaz y "no se puede vivir libre, no ya [por] un breve espacio de tiempo, sino ni un minuto siquiera" ${ }^{45}$. República y corrupción es una pareja de realización imposible.

DE INCONVENIENTE NECESARIO A CONDICIÓN INDISPENSABLE: EL LUGAR DEL antagonismo EN La TeOría POLÍtica de John STUART MILL

Tres siglos después, y desde otras latitudes, John Stuart Mill también se mostró particularmente interesado por los efectos positivos que podían derivarse de la existencia de la conflictividad entre los hombres. Como se indicó previamente, Mill conocía los principales textos de Maquiavelo, aunque muy pocas veces lo cita y, hasta donde sé, en ningún lugar de su obra se detiene a discutir abiertamente con el florentino sobre su visión de la política. No es posible aseverar, por tanto, que las intuiciones de Maquiavelo que se presentaron en el punto anterior hayan tenido un impacto directo sobre el pensador inglés. Como se verá a continuación, Mill aborda la problemática del antagonismo interpelado por desafíos ausentes en la Florencia del siglo dieciséis y lo hace desde aristas no transitadas por Maquiavelo. Aun así, creo que es posible advertir en ambos la presencia de

\footnotetext{
${ }^{41}$ Ibid., I, 18, p. 86.

${ }^{42}$ Ibid, p. 87.

${ }^{43}$ HILB, "Maquiavelo, la república y la virtù", p. 141.

${ }^{44}$ Maquiavelo, Discursos sobre la primera década de Tito Livio, I, 17, p. 83.

${ }^{45}$ Ibid., I, 16, p. 77.
} 
una premisa compartida, aquella que encuentra necesario tolerar o rehabilitar (según el caso) los conflictos que naturalmente recorren toda sociedad si lo que se anhela es, ante todo, evitar la dominación y permitir la grandeza, el crecimiento y el progreso, si — antes que la estabilidad — lo que se prioriza es el cambio.

\section{Antagonismo, libertad y progreso}

El interés de Mill por el conflicto o el antagonismo se encuentra anudado en una preocupación que lo acompañó a lo largo de su vida, pero que se manifestó por primera vez con particular fuerza en torno a la década de 1830. Una década signada por los primeros pasos en su recorrido intelectual más autónomo, en la que gracias a los diversos autores a los que frecuentó y leyó, el estrecho credo en el que había sido formado fue dando lugar a un pensamiento que él mismo gustaba llamar "ecléctico"46. Entre otros, fue su contacto con Tocqueville el que le permitió poner en palabras lo que hasta entonces había sido una persistente intuición: el principal peligro que amenaza a las sociedades modernas y frente al cual es preciso luchar sin descanso es el estancamiento o la inmovilidad ${ }^{47}$.

El estancamiento es un mal que se despliega tanto en el ámbito moral e intelectual como en la arena política. Una sociedad cuya vida política está estancada es una sociedad en la que la política ha caído en un inquietante reposo, una sociedad que ha perdido vitalidad y se halla desprovista de dinamismo interno. El estancamiento político se identifica con la conservación de lo adquirido, la priorización del orden y la aparente estabilidad por sobre el cambio y el progreso; con el temor a las innovaciones, el recelo frente a las tensiones, la rutina y el aval dispensado al curso adoptado por los pocos que detentan el poder. Este tipo de inmovilidad, que semeja un estado de ensueño o semi vigilia, convierte a la sociedad en un terreno propicio para el advenimiento del despotismo (ya sea en su versión cesarista como bajo su rostro moderno: el despotismo de tipo administrativo que ejerce un poder centralizado y tentacular). No se confunde con él, pero ciertamente lo favorece: un pueblo adormecido se deja arrebatar fácilmente la libertad, en tanto que carece de las disposiciones necesarias para retenerla. Por su parte, el estancamiento moral e intelectual es caracterizado por Mill como un estado de "pacificación intelectual", que se encuentra signado por la ausencia de

46 John Stuart MiLl, “Autobiography”, en Collected Works, vol. I, Autobiography and Literary Essays, p. 156; y la Carta enviada a Gustave d'Eichthal (7 de noviembre de 1829), en Collected Works, vol. XII, The Earlier Letters of John Stuart Mill 1812-1848 Part I, p. 42.

${ }^{47}$ John Stuart MiLl, Carta enviada a Alexis de Tocqueville (11 de mayo de 1840), en Collected Works, vol. XIII, The Earlier Letters of John Stuart Mill 1812-1848 Part II, p. 434. 
grandes controversias, la escasez de convicciones fuertes y pasiones elevadas; un estado en el que el espíritu humano se rebaja, se embota, se atrofia y en el que prima una creciente uniformidad en materia de ideas, sentimientos, gustos y hábitos. Este tipo de estancamiento también supone un estado de mediocridad y dogmatismo en el que tanto el desarrollo de la inteligencia como el cultivo de la individualidad implican una verdadera hazaña. Sobre semejante escenario, además, se erige lentamente un nuevo actor social capaz de oprimir y cercenar las libertades individuales: la opinión pública. Su imperio da lugar a lo que él denomina la tiranía de la opinión, aquella que no mata ni ataca directamente el cuerpo de los hombres sino que va derecho al alma y la esclaviza. Despotismo y estancamiento forman parte de un círculo vicioso que se retroalimenta y que se traduce, en definitiva, en el "sacrificio del coraje moral del espíritu humano"48.

Para Mill se trata de un fenómeno estrechamente vinculado con las sociedades civilizadas, puesto que hunde sus raíces en los cambios que trae aparejados el avance de la civilización: entre otros, el crecimiento de las masas; la debilidad, opacidad y desorientación de los individuos; el creciente individualismo y la desafección pública y la preeminencia del espíritu comercial que lleva a que los hombres prioricen su bienestar material, circunscriban sus energías y aspiraciones en empresas poco elevadas, limiten sus ambiciones y vean diluida su esfera de autonomía individual. Pero el principal lazarillo, el verdadero asiento del estancamiento es la uniformidad en materia intelectual y la homogeneidad en el cuerpo social. En este sentido, el estancamiento se convierte en una amenaza siempre latente que se cierne sobre toda sociedad en la que uno de los poderes o grupos que la integran se impone de manera hegemónica sobre el resto, ahogando de este modo el sano y fecundo antagonismo capaz de mantenerla viva. Parafraseando y generalizando una de sus famosas sentencias contenida en $O n$ Liberty, el verdadero peligro no consiste en el conflicto, sino en la supresión del mismo ${ }^{49}$.

Vemos entonces que, por la vía negativa, la ausencia o la supresión del conflicto conduce a un escenario en el que la libertad individual se ve restringida. Ahora bien, si reparamos al mismo tiempo en lo que podríamos llamar la vía positiva en su argumentación, encontraremos que para Mill la aceptación del antagonismo resulta una "condición indispensable" para el progreso, tanto en términos individuales como sociales. Esta vinculación (conflicto-progreso-libertad)

${ }^{48}$ Estas expresiones se encuentran en John Stuart MiLl, "On Liberty", en Collected Works, vol. XVIII, Essays on Politics and Society Part I, p. 242.

${ }^{49}$ Ibid., p. 257; María Pollitzer, "John Stuart Mill y el peligro del estancamiento en las sociedades modernas": Estudios Públicos, n. ${ }^{\circ} 128$ (2012), pp. 89-113. 
hunde sus raíces en su concepción etológica y guarda estrecha relación con sus presupuestos gnoseológicos y su teoría de gobierno. Como es sabido, la cuestión de la formación del carácter era uno de los temas de debate ético político en boga durante la época victoriana y Mill se hizo eco del mismo en varios de sus escritos. De hecho, en el libro VI de su System of Logic presenta los rasgos esenciales de lo que habría de constituir la nueva ciencia de la Etología, una suerte de ciencia puente entre la Sociología y la Psicología, llamada a cartografiar la naturaleza humana o, más precisamente, a descubrir las leyes universales que orientan la formación de los diversos caracteres individuales y nacionales. Estaba convencido - contrariamente a lo que sostenía la prédica owenista en la que había sido educado - de que "somos exactamente tan capaces de formar nuestro propio carácter si queremos, como otros lo son de formarlo para nosotros" ${ }^{50}$. Ello le permite sostener que los hombres pueden corregir y reencauzar el propio carácter, siempre que se sometan a influencias y circunstancias diferentes de aquellas bajo las que hasta entonces se habían situado. El resultado de la colisión entre influencias diversas es fecundo, permite superar las limitaciones y los sesgos inevitables que toda instancia de educación contiene y redunda en el crecimiento moral e intelectual de los individuos. En resumidas cuentas, así como el carácter de los individuos es pasible de ser re-direccionado, lo mismo sucede con el carácter de los pueblos. Pero para ello es indispensable permitir la coexistencia, en su seno, de diferentes ideas, pasiones y sentimientos, e incluso estimular aquellas que puedan actuar como contra-tendencias frente a las que predominan en un determinado tiempo.

Respecto de los presupuestos gnoseológicos sobre los que se asienta esta concepción, es preciso recordar que para Mill la verdad tiene un carácter eminentemente dinámico. Como escribe en una ocasión, ella "es militante y no puede establecerse más que por medio del combate" 51 . La verdad solo se revela a los hombres de manera progresiva y como resultado de una confrontación de opiniones parciales que siempre sigue abierta. El asunto es que, en su opinión, el verdadero progreso mental y moral se consigue cuando los intelectos se encuentran en una "colisión estimulante", que es la que permite a cada parte adquirir aquellas nociones a las que no hubiera arribado por sí sola ${ }^{52}$. Por otra parte, en

\footnotetext{
${ }^{50}$ John Stuart MiLl, "A System of Logic Ratiocinative and Inductive”, en Collected Works, vol. VIII, A System of Logic Part II, p. 840.

${ }^{51}$ Ibid., vol. VII, A System of Logic Part I, p. 115.

${ }^{52}$ John Stuart MiLl, "The Principles of Political Economy", en Collected Works, vol. II, Principles of Political Economy Part II, p. 209. En su artículo sobre Bentham ejemplifica este punto diciendo que "todo pensador (inquirer) es joven o viejo, rico o pobre, enfermo o sano, casado o
} 
On Liberty afirma que sin un saludable conflicto entre ideas, las verdades que alguna vez gozaron de vitalidad y energía simplemente se estancan y se mantienen tan solo como dogmas muertos. Tomar conciencia de este mal debe llevarnos a combatir y erradicar "el principio mismo de una religión dogmática, una moralidad dogmática [y] una filosofía dogmática...no una manifestación particular de este principio"53. Por lo demás, la aceptación de esta mirada constituye, a su juicio, "la única base racional y perdurable de la tolerancia filosófica, la única condición bajo la cual la liberalidad en materia de opinión puede ser algo mejor que un sinónimo educado para la indiferencia entre una opinión y otra ${ }^{54}$. En el fondo, para Mill, la existencia de modos de pensamiento antagónicos es, en materia especulativa, lo que los poderes mutuamente controlados son en una constitución política, lo que nos conduce al último punto que habíamos anticipado.

La idea de que el antagonismo no es tan solo un componente ineludible de la vida social y política sino que tiene un valor normativo, es decir, que debe ser estimulado y reconocido también por las instituciones políticas es tributaria, en Mill, de su lectura de las obras de Samuel Taylor Coleridge (1772-1834) y François Guizot (1787-1874). Del poeta romántico rescata al menos dos lecciones: primero, la necesidad que toda sociedad tiene de contar con una clerecía intelectual y segundo, la tesis de que todos los intereses presentes en una sociedad civilizada se encuentran comprendidos por dos grandes fuerzas a las que denomina Permanencia y Progreso. Según Coleridge estas representan "poderes antagónicos e intereses opuestos", uno vinculado con los propietarios de la tierra y el otro con las clases mercantiles, manufactureras, distribuidoras y profesionales. Aclara que se trata de poderes opuestos aunque no contrarios, los cuales (como sucede con los polos magnéticos) se suponen y requieren mutuamente ${ }^{55}$. Aunque Mill no coincide exactamente con la identificación que Coleridge propone entre ambas fuerzas y sus respectivos grupos sociales ${ }^{56}$ sí comparte la idea de que el

soltero, meditativo o activo, poeta o lógico, antiguo o moderno, hombre o mujer, y si es una persona pensante tiene además las particularidades accidentales de su modo de pensamiento individual". John Stuart Mill, "Bentham", en Collected Works, vol. X, Essays on Ethics, Religion, and Society, pp. 90-91. Esta es la razón por la cual cada uno tiende a percibir ciertas cosas con mayor profundidad pero a desatender y olvidar otras.

${ }^{53}$ MiLL, "On Liberty", p. 144.

${ }^{54}$ John Stuart MiLl, "Coleridge", en Collected Works, vol. X, Essays on Ethics, Religion, and Society, p. 122.

${ }^{55}$ Samuel Coleridge, On the Constitution of Church and State according to the Idea of Each, Harte, Chance and Co, London, 1830, p. 18.

${ }^{56}$ John Stuart Mill, Carta enviada a John Sterling (2 de octubre de1839), en Collected Works, vol. XIII, The Earlier Letters of John Stuart Mill 1812-1848 Part II, p. 409. 
progreso social recorre un camino dialéctico, que la rivalidad entre las fuerzas no desaparece y que ambas deben encontrar su lugar de representación en el ordenamiento institucional, desde donde habrán de contrabalancearse.

Apenas unos años después de haber leído a Coleridge, hacia 1832, Mill tomó contacto con las obras de Guizot y dedicó dos artículos para analizar en detalle las reflexiones del historiador francés ${ }^{57}$. Uno de los puntos que llamó particularmente su atención fue la premisa en la cual Guizot hacía descansar el progresivo avance de la civilización europea en contraposición a los estados orientales, es decir, la existencia - en el último caso- de una puja constante y necesaria entre diversos principios, poderes e ideas. En el primer artículo, Mill cita textualmente el pasaje en el que Egipto e India son utilizados como ejemplos de sociedades signadas por la primacía de la unidad: sus instituciones, sus costumbres, sus creencias parecen emanados de una sola fuerza, de un principio único. Guizot reconoce que en la vida de esos pueblos han existido períodos de lucha entre principios rivales, pero cree que estos se encuentran circunscritos a los inicios de su historia. Tales combates no fueron más que "una crisis pasajera" o un "accidente" incapaz de impedir que finalmente una de las fuerzas en pugna terminara venciendo y tomando el control exclusivo del conjunto de la sociedad. "La simplicidad acarreó la monotonía" y esta la inmovilidad ${ }^{58}$. En contrapartida, la historia de la civilización europea proyecta la imagen de un stormy chaos: desde sus inicios convivieron en su seno una pluralidad de principios, ideas, elementos, sistemas de instituciones o poderes que lucharon entre sí de manera constante sin que ninguno de ellos consiguiera imponerse de manera hegemónica sobre el resto. En el segundo artículo, Mill vuelve sobre estas ideas e introduce el concepto de "antagonismo sistemático" 59 para graficar aquello que considera "la única condición bajo la cual la estabilidad y el progreso pueden ser reconciliados de manera permanente" ${ }^{60}$. Sucede que, además de brindarle una proyección histórica a sus propias intuiciones y a las ideas legadas por Coleridge, la lectura de la historia propuesta por Guizot contenía una advertencia que Mill supo percibir: el estancamiento no era un mal privativo del pasado o acaso

${ }^{57}$ El primero, "Guizot's Lectures on European Civilization”, fue publicado en 1836 en la London Review y el segundo, "Guizot's Essays and Lectures on History", en octubre de 1845 en la Edinburgh Review.

${ }^{58}$ François GuIzot, Historia de la civilización en Europa, Alianza Editorial, Madrid, 1968, p. 42.

${ }^{59}$ En una carta dirigida a Auguste Comte el 25 de febrero de 1842, Mill utiliza la expresión "antagonismo indispensable". Collected Works, vol. XIII, The Earlier Letters of John Stuart Mill 1812-1848 Part II, p. 503.

${ }^{60}$ John Stuart MiLl, "Guizot's Essays and Lectures on History", en Collected Works, vol. XX, Essays on French History and Historians, pp. 269-270. 
de las sociedades orientales, sino un peligro que se asoma toda vez que el antagonismo da paso a la preponderancia de cualquier elemento dentro de la sociedad, "incluso el más saludable"

Mill hizo suyas estas enseñanzas y las reiteró en varios escritos ${ }^{62}$. A modo de ejemplo, en su ensayo sobre Bentham cuestiona precisamente la confianza que algunos depositaban en el gobierno absoluto de las mayorías. Reconoce que siempre hay un poder supremo en toda sociedad y cree que la mayoría debe ser tal poder. Pero advierte que:

Allí donde hay identidad de posición e intereses, también habrá identidad de parcialidades, pasiones y prejuicios, y darle a cualquiera de estos conjuntos de parcialidades, pasiones y prejuicios, el poder absoluto...es la manera de convertir un estrecho y mezquino tipo de naturaleza humana en universal y perpetuo, y de aplastar toda influencia que tienda al progreso de la naturaleza intelectual y moral del hombre ${ }^{63}$.

Por ello, recuerda la necesidad de que las instituciones prevean la forma de mantener viva una "oposición perpetua y de pie" frente a la voluntad de esta mayoría, "como un correctivo frente a las miradas parciales, y como refugio para la libertad de pensamiento y la individualidad del carácter" ${ }^{4}$. Y a continuación refuerza su argumento valiéndose de ejemplos tomados de la historia. Señala que todos los países que han progresado durante mucho tiempo o que han alcanzado una grandeza duradera, lo han conseguido precisamente porque conocieron una oposición de pie frente al poder de turno: "plebeyos contra patricios, el clero frente a los reyes, los librepensadores frente al clero, los reyes contra los barones, los comunes frente al rey y la aristocracia" ${ }^{65}$. Por contrapartida, aquellas sociedades en las que esta pelea cesó tras el triunfo completo de uno de los principios contendientes, el resultado fue el estancamiento, la caída y la disolución. Es claro que aquí Mill está siguiendo la pluma de Guizot. Sin embargo, es interesante notar que el historiador francés no había señalado en sus Lecciones la oposición entre patricios y plebeyos como ejemplo del punto que quería marcar.

61 Ibidem.

${ }^{62}$ John Stuart MiLL, "De Tocqueville on Democracy in America [II]", en Collected Works, vol. XVIII, Essays on Politics and Society Part I; "Duveyrier's Political Views of French Affairs", en Collected Works, vol. XX, Essays on French History and Historians; "Bentham" y "Considerations on Representative Government".

${ }^{63}$ MiLl, "Bentham", p. 107.

${ }^{64}$ Ibid., p. 108.

65 Ibidem. 
Antes bien, Roma y Grecia estaban incluidas dentro del conjunto general de sociedades simples, emanadas de un único principio. ¿Será esta una concesión implícita a Maquiavelo? No podemos probarlo, pero no deja de resultar llamativo. En cualquier caso, Mill está convencido de que cuando se impone una única fuerza, un único poder, los derechos de los individuos están en peligro, y es por ello que considera imperioso que el orden institucional vea la manera de establecer "un centro de resistencia alrededor del cual todos los elementos morales y sociales que son vistos con disfavor por el poder gobernante puedan reunirse y encontrar refugio frente al intento de parte del poder de borrarlos de la existencia"66.

En síntesis, así como en el ámbito intelectual y moral un clima de libertad es condición para que florezca el antagonismo y este, a su vez, dé cabida al progreso, en el ámbito socio-político es el antagonismo sistemático entre diversos grupos el que mantiene a resguardo las libertades individuales. El conflicto, cual impulso vivificante, no está llamado, pues, a ser superado en una instancia pacificadora sino a mantenerse siempre activo y fecundo.

\section{Ámbitos y estrategias para mantener vivo el antagonismo}

\section{Ámbito institucional}

La preocupación por darle una forma institucional a estas ideas en torno a la conveniencia y la utilidad del antagonismo se apoya sobre la convicción de que Inglaterra había dejado de ser una "aristocracia con una infusión popular" y se estaba convirtiendo en un "régimen de las clases medias"67. El reconoce que la ascendencia de este grupo en el plano social y político es inevitable e irresistible. Peligrosa, solo si se convierte en el único poder. Tres son las opciones analizadas para mantener vivo el antagonismo y encuadrarlo institucionalmente en este nuevo escenario: la conveniencia o no de un sistema bicameral para emplazar al poder legislativo, el voto plural o acumulativo y la representación proporcional.

De las tres, la que menos importancia reviste para Mill es la primera. Si en un sistema bicameral la composición de las dos cámaras es semejante, ambas estarán sometidas a las mismas influencias, por lo que una difícilmente pueda actuar como freno de la otra. Tampoco lo convence el argumento de quienes creen que la existencia de una segunda cámara combate la precipitación en la toma de decisiones al imponer una segunda deliberación (mecanismo que podría

\footnotetext{
${ }^{66}$ Ibidem.

${ }^{67}$ MiLl, "Considerations on Representative Government", p. 422.
} 
y debería darse en todo debate, inclusive en aquellos que tengan lugar el seno de una sola cámara). Lo único que admite es que sin una segunda instancia de aprobación, las decisiones que la cámara adopte se verán libres de la necesidad de dar cuenta y fundamentar las razones que las sostienen, lo que puede allanar el camino a la tendencia propia de todo soberano único: el despotismo. Si por el contario, la composición de ambas cámaras es desigual, el asunto a considerar es si la segunda cámara cuenta con apoyo social por fuera del Parlamento: si su composición se rige por el criterio de la mera riqueza o el nacimiento (como la de los Lores), resulta un remedio anacrónico e ineficaz. Si, en cambio, se presenta como un asiento para los grandes estadistas (al estilo del Senado Romano) o de los sectores administrativos, dotados de experiencia, conocimiento y talento, su efecto puede ser altamente beneficioso, en la medida en que permite el control y el estímulo recíproco y constante entre la "capacidad" y la "participación" (encarnada en la cámara de composición popular). En cualquier caso, para Mill, el verdadero poder moderador en una sociedad moderna "debe obrar en y por la cámara democrática". En su opinión, el modo de fortalecer a un partido débil, que en este caso sería el sector integrado por los más ilustrados y capaces, no consiste en presentarlo como a un ejército enemigo y colocarlo en la línea de batalla frente a su adversario más poderoso. Por el contario, lo que se precisa es situarlo entre la multitud y dejar que opere "como uno de los elementos de la masa, infundiéndole su levadura y...dando preponderancia al partido que, sin el apoyo de su influencia hubiese sido el más débil" ${ }^{\prime 68}$.

Confiar en que el antagonismo tenga lugar en el seno de la cámara democrática implica idear mecanismos de representación que la conviertan en un espejo de la diversidad existente en la sociedad y que permitan el acceso a sus filas de los todos los sectores, inclusive los más debilitados. Es en esta línea que, tanto en "Thoughts on Parliamentary Reform" como en el capítulo VIII de sus Consideraciones sobre el Gobierno Representativo Mill defiende el voto plural. Su argumento parte de la distinción entre el derecho al voto, que eventualmente debería extenderse a todos los hombres, y el supuesto de que el peso de ese voto deba ser igual en todos los casos. Solamente es necesario establecer con claridad y justicia el criterio en base al cual habrá de establecerse un esquema que contemple la pluralidad de los votos. Mill rechaza de plano un criterio de tipo económico; la graduación que propone se asienta sobre uno de tipo educativo. Pero hasta tanto tenga lugar un sistema de evaluación general y una mejora sustancial

\footnotetext{
${ }^{68}$ Ibid., pp. 514-515.
} 
en la educación del país, concede que la ocupación de cada hombre sirva como testimonio de su capacidad mental.

Por último, Mill suscribe a la propuesta elevada por Thomas Hare consistente en un nuevo mecanismo que permitiría la representación proporcional al número de cada división del cuerpo electoral. Es decir, daría cabida no solo a los grandes partidos, sino también a cualquier minoría que contase con los votos suficientes para tener un representante. Con ello, la pluralidad de opiniones, sentimientos e ideas dispersos en la sociedad tendrían la oportunidad de ser escuchados en el Parlamento, un asunto de vital importancia para Mill, quien afirma en una ocasión que:

En ausencia de sus defensores naturales, el interés de los excluidos siempre está en riesgo de ser desestimado, y cuando se lo considera, se lo hace con ojos diferentes a los que tendrían las personas a las que les conciernen directamente ${ }^{69}$.

Además, al liberar a los votantes de la obligación de elegir a quienes se proponían en sus propias localidades, el proyecto de Hare hacía posible que los hombres dieran su voto a aquellas personalidades que se destacaran por su reputación nacional. Si bien lo más probable es que el número de estos individuos fuera reducido, su mera presencia en el Parlamento elevaría el tono del debate, arrojaría luz sobre la mediocridad generalizada y permitiría a toda opinión disidente o contraria respecto de la mayoritaria la oportunidad de hacerse oír.

\section{Ámbito social}

Ahora bien, de nada sirve idear mecanismos o instituciones que den cabida a la diversidad si no hay diversidad que representar. Es decir, si la sociedad se vuelve cada vez más homogénea y uniforme. Es por ello que, frente al predominio cada vez más importante que están teniendo las clases medias en las sociedades modernas o civilizadas, Mill invita a que, junto a ella, coexistan otras clases que oficien de contrapeso. En su reseña del segundo volumen de La democracia en América sostiene que el espíritu comercial (propio de las clases medias) debería ser atemperado y contrarrestado por la presencia de otras clases infundidas por intereses, hábitos e ideas distintos a este. Menciona, así, la necesidad de una clase agrícola, una clase ociosa y una clase letrada o culta. Su alegato a favor de la

\footnotetext{
${ }^{69}$ John Stuart MiLL, "Recent Writers on Reform", en Collected Works, vol. XIX, Essays on Politics and Society Part II, p. 358.
} 
segunda en este texto no resulta del todo convincente ni coherente con lo manifestado en el resto de sus obras ${ }^{70}$, por lo que nos centraremos únicamente en las otras dos.

Mill cree que el hombre que integra la clases agrícolas encarna el "tipo opuesto" al de aquel inmerso en el espíritu comercial. Entre las virtudes particulares de este último anota la integridad, la economía, la iniciativa y el deseo de independencia; virtudes que conviven a su vez con ciertas debilidades: la pasión creciente por el dinero y la búsqueda constante del bienestar material, la indiferencia hacia el cultivo intelectual que no redunde en un beneficio inmediato, el apego al tiempo presente, la escasa capacidad para percibir y gozar con la belleza, la circunscripción de la energía individual en una esfera muy reducida y la pérdida del espíritu heroico. Por su parte, el hombre que proviene de las clases agrícolas se muestra siempre dispuesto a buscar y a aceptar la guía de los otros, tiene "deseos moderados, gustos tranquilos y cultiva los placeres y diversiones que tiene a su mano" "'. Se caracteriza por el apego a su tierra, que se acompaña del apego a su gente y a su propia ocupación. Además, las tareas agrícolas dejan poco espacio para que el gusto excesivo por los bienes materiales y el dinero alcancen dimensiones preocupantes, de manera que este hombre se satisface con menos ganancias y está menos impaciente por conseguirlas. Esta mirada elogiosa respecto del "espíritu agrícola" se manifiesta también en los artículos reunidos bajo el título de "The Condition of Ireland" (1846), como en su Principles of Political Economy (1848). En este último, en el marco de su argumentación a favor de la propiedad campesina, Mill afirma que ella no solo estimula la actividad mental de los hombres sino que también los previene del egoísmo y la estrechez intelectual, al tiempo que suscita en ellos virtudes morales tales como la prudencia, la temperancia y el autocontrol.

El otro grupo que debe oficiar de contrapunto frente a la clase media es aquel que se encuentra integrado por los sectores más ilustrados. La postura de Mill respecto del modo en que este grupo debe actuar y los medios a través de los cuales conviene que lo haga fue variando con el tiempo, pero él nunca abandonó la convicción sobre la necesidad de su presencia. Influido por la idea saintsimoniana del poder espiritual y la noción de clerisy propuesta por Coleridge, Mill concibe la clase letrada en un sentido amplio. No la identifica con un cuerpo organizado, integrado por hombres con atribuciones determinadas, sino más

${ }^{70}$ John Stuart Mill, Carta enviada a John Austin (13 de abril de 1847), en Collected Works, vol. XIII, The Earlier Letters of John Stuart Mill 1812-1848 Part II, pp. 711-715; y "De Tocqueville on Democracy in America [II]", p. 195.

${ }^{71}$ MiLl, "De Tocqueville on Democracy in America [II]", p. 198. 
bien como un grupo social que engloba a todos aquellos que han dedicado sus vidas al cultivo intelectual en cualquiera de sus campos, hombres destacados por su talento e instrucción, "maestros del conocimiento", capaces de liderar y exhortar en otros el cumplimiento de los derechos y los deberes ${ }^{72}$. Su propuesta entonces, no consiste en instaurar una aristocracia intelectual por sobre un pueblo que permanece en las tinieblas. Nada más peligroso que mantener "la inteligencia y el talento...en un alto nivel entre la corporación gobernante, pero esca-

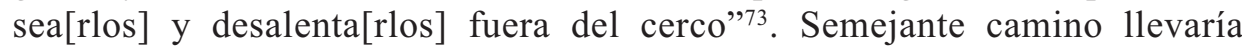
directamente al despotismo, en la medida en que dota a quienes ya poseen el poder legal de un "arma adicional": la superioridad intelectual. Martín Hopenhayn cree que la idea de Mill es que la inteligencia de esos pocos cumpla funciones educativas pero no coactivas y lo haga a través de la persuasión y no de la coacción ${ }^{74}$. En opinión de Eisenach, los miembros de esta clerecía están llamados a actuar como guías o, más precisamente, como una suerte de reseñadores o críticos literarios ${ }^{75}$. Su tarea no debe consistir primeramente en inventar o imponer nuevas ideas al resto de la comunidad sino en la búsqueda e integración de aquellos aspectos de verdad que se encuentran escondidos tanto en las opiniones polémicas del día como en las diferentes corrientes que han contribuido a forjar el pensamiento de la humanidad. Bajo esta lógica, se comprende que Mill haya pensado en la prensa periódica como una de sus plataformas. Con el correr de los años y las reformas implementadas en las universidades a mediados de siglo, su mirada comenzó a contemplar también al ámbito académico como una base alternativa para este grupo. En última instancia, ambas (prensa y universidad) eran canales a través de los cuales se podía alentar la formación de espíritus autónomos y, así, contribuir en la defensa de un orden plural.

72 John Stuart Mill, Carta enviada a John Sterling (20 de octubre de 1831), en Collected Works, vol. XII, The Earlier Letters of John Stuart Mill 1812-1848 Part I, p. 76.

${ }^{73}$ MiLl, "Principles of Political Economy", p. 943. John Stuart MiLl, Carta enviada a Alexander Bain (6 de agosto de 1859), en Collected Works, vol. XV, The Later Letters of John Stuart Mill 1849-1873 Part II, p. 631.

${ }^{74}$ Martín Hopenhayn, "La libertad y la tentación de la excentricidad": Estudios Públicos, vol. 46 (1992), pp. 95-112.

${ }^{75}$ EISENACH, "Self-Reform as Political Reform in the Writings of John Stuart Mill”, pp. 256258. 


\section{Ámbito individual}

Según relata su amigo John Sterling, Mill fue educado en la creencia de que las instituciones políticas y sociales "lo eran todo", pero con el tiempo llegó a descubrir que "la reforma individual debía ser [el trabajo preliminar] del progreso social" ${ }^{\prime}$. De ahí la importancia asignada a la educación impartida directa o indirectamente, tanto desde el seno de la familia como desde las instituciones superiores como las universidades. A diferencia de Maquiavelo, Mill estaba convencido de que los hombres pueden modificar y corregir su carácter y el modus operandi para conseguirlo se basa precisamente en la lógica de la confrontación: en el plano racional, por ejemplo, anima a dejarse interpelar por opiniones e ideas diferentes a las propias, que "sacudan" los cimientos sobre los que estas se erigen y revelen al mismo tiempo aspectos de verdad que no se habían contemplado previamente. Mill no valora únicamente el costado destructivo que trae aparejado todo conflicto, el mero desacuerdo o la mera constatación de los errores ajenos o propios no asegura de por sí el progreso. A ello ha de sumarse su potencial constructivo: solo tras la confrontación es posible arribar a una instancia superadora, a una visión más abarcadora y más completa de la que se tenía, y abrazar nuevos valores y nuevas ideas. Pero esta nueva instancia es también transitoria y, como tal, está destinada a ser corregida y mejorada a lo largo de toda la vida, en lo que respecta a cada individuo, a lo largo de la historia de la humanidad, si pensamos en el género humano en su conjunto.

Reencauzar el carácter de los hombres implica, a su vez, atender a su dimensión pasional. Mill había aprendido esta lección en carne propia y de manera desgarradora tras la crisis sufrida a los veinte años. A partir de entonces, "el cultivo de los sentimientos se convirtió en uno de los puntos cardinales de [su] credo ético y filosófico" "77. Concedió especial atención al desarrollo de la simpatía, a la que estimaba como principal antídoto frente al creciente individualismo. Mill creía que este sentimiento se nutría de la imaginación, que no encontraba su fuente en la lógica (formadora más bien de hábitos analíticos), sino en su "antagonista", la poesía ${ }^{78}$. Fue la lectura de los poemas de William Words-

\footnotetext{
${ }^{76}$ Caroline Fox, Memories of Old Friends, Horace N. Pym, London, 1882. Citado en Joseph Hamburger, John Stuart Mill on Liberty and Control, Princeton University Press, Princeton, New Jersey, 1999, p. 20.

${ }^{77}$ MiLl, "Autobiography”, p. 147.

${ }^{78}$ John Stuart MiLL, "Thoughts on Poetry and its Varieties", en Collected Works, vol. I, Autobiography and Literary Essays, p. 361 y "Sedgwick's Discourse", en Collected Works, vol. X, Essays on Ethics, Religion, and Society, p. 39.
} 
worth (1770-1850) la que le reveló la estrecha relación que media entre la poesía y la simpatía. La primera no está llamada a provocar únicamente el deleite entre sus lectores, sino que bien puede instruir a los mismos despertando y fomentando en ellos un sentimiento de benevolencia genuina, un sentimiento que podría actuar de contrapeso frente sus tendencias egoístas. En vistas de ello, Mill no dejó de insistir en la idea de que una educación adecuada era aquella que incluía saberes y disciplinas dirigidas tanto a la formación del intelecto como de los afectos.

\section{A modo de conclusión: ecos Maquiavélicos en John Stuart Mill}

En función del recorrido realizado por las obras de los autores escogidos, con la intención de examinar la manera en que ambos vincularon el conflicto con la libertad es posible arribar a las consideraciones que se detallan a continuación.

En primer lugar, tanto para Maquiavelo como para Mill, la existencia de conflictos en la sociedad se anuda en la misma naturaleza humana y, por lo tanto, los consideran naturales e inextirpables. Sus análisis parten, pues, del reconocimiento y la aceptación de la diversidad irreductible de la sociedad. Maquiavelo reduce dicha diversidad a dos grandes pasiones que inclinan el obrar humano: el deseo por dominar y el deseo a no ser dominado. Mill reconoce la presencia de estas pasiones pero afina el diagnóstico y encuentra que los conflictos se originan en múltiples niveles y obedecen tanto a los intereses de clase como a los sesgos parciales contenidos en los deseos, opiniones y sentimientos de cada individuo.

En segundo lugar, en Maquiavelo persiste una mirada desconfiada, o más bien, una mirada que tolera el conflicto porque estima que es posible encontrarle un efecto beneficioso a largo plazo o de modo indirecto. Lo visualiza como un mal necesario. En cambio, la mirada de Mill, un ardiente polemista, es menos recelosa. Para él los conflictos no solo deben ser tolerados, sino también alentados. Es probable que el contexto en el que cada uno vivió haya influido, en parte, para atemperar (en un caso) o atizar (en otro) la apreciación de los mismos. Una Inglaterra amenazada por el peligro del estancamiento presenta desafíos distintos y pone en primer plano preocupaciones ausentes o lateralizadas en una Florencia con una historia de luchas intestinas detrás, inmersa, a su vez, en una Italia presa de rivalidades políticas de todo tipo.

En cualquier caso, para ambos, la eliminación del conflicto da lugar a un estado de quietud que resulta engañoso y peligroso. Engañoso, si lo que se esconde bajo un aparente consenso y un anhelo de estabilidad es más bien una forma de dominación de un grupo sobre la totalidad, dominación que se ejerce tanto en 
el ámbito político como en el social. Si bien Maquiavelo concentra su mirada sobre la dimensión política, su lectura sobre los efectos negativos que produjo el accionar del pueblo florentino en su enfrentamiento con los grandes (fue el intento del pueblo por imponer sus propias opiniones, costumbres y modo de vivir al resto lo que condujo al deterioro de la ciudad) tiene un aire de familia con los resultados nocivos que Mill adjudica a cualquier tentativa de homogeneización social. Y peligroso, porque conduce a un escenario de debilidad en el que la ciudad no es capaz de hacer frente a los cambios que inevitablemente se presentarán, no puede alcanzar la grandeza o el progreso y se muestra desprotegida frente al avance de nuevos despotismos. Así, antes que la presencia de conflictos, es su ausencia el síntoma que debe despertar preocupación. Pues allí se delata una situación en la que la libertad (del individuo y de la ciudad) se ve amenazada.

En conclusión, tanto Maquiavelo como Mill consideran que uno de los objetivos centrales de la política es procurar institucionalizar los conflictos en lugar de anularlos o subyugarlos. Ella debe idear mecanismos que encaucen legalmente y permitan expresarse a las distintas voces, deseos, intereses y sentimientos que recorren la sociedad. En este sentido, creo que la propuesta maquiavélica de una república pensada como desunión, es decir, como un orden político que no aspira en primer lugar a forjar la concordia ordinum (tal como anhelaba en el republicanismo clásico), sino que se presenta como una alternativa capaz de mantener un equilibrio dinámico fuerzas, pasiones e intereses antagónicos sin recaer en un escenario de licenza y evitando, al mismo tiempo, la dominación tanto de uno como de un grupo sobre el resto, guarda estrecha relación con la forma en la cual Mill piensa un régimen representativo que pueda dar cabida a las minorías. Para el inglés, solo este puede ofrecer los espacios o los órganos necesarios para preservar la diversidad, la heterogeneidad y la disidencia en una sociedad signada por la tendencia a la uniformidad que se corresponde con el avance de las mayorías. Solo este entramado da lugar a una democracia verdadera, aquella que se sostiene sobre - y al mismo tiempo promueve- la libertad y la igualdad.

\section{REFERENCIAS BIBLIOGRÁFICAS}

Bock, Gisela; Skinner, Quentin; y Viroli, Maurizio (eds.), Machiavelli and Republicanism, Cambridge University Press, Cambridge, 1990.

Coleridge, Samuel, On the Constitution of Church and State according to the Idea of Each, Harte, Chance and Co, London, 1830.

EISENACH, Eldon J., "Self-Reform as Political Reform in the Writings of John Stuart Mill”: Utilitas, vol. I, n. ${ }^{\circ}$ (1998), pp. 242-258. 
Funes, Ernesto, La Desunión. República y no-dominación en Maquiavelo, Buenos Aires, Editorial Gorla, Buenos Aires, 2004.

Guizot, François, Historia de la civilización en Europa, Alianza Editorial, Madrid, 1968.

Hamburger, Joseph, John Stuart Mill on Liberty and Control, Princeton University Press, Princeton, New Jersey, 1999.

Hilb, Claudia "Maquiavelo, la república y la virtù", en Tomás VÁrnagy (comp.), Fortuna y virtud en la república democrática. Ensayos sobre Maquiavelo, CLACSO, Buenos Aires, 2000.

HoPENHAYN, Martín, "La libertad y la tentación de la excentricidad": Estudios Públicos, vol. 46 (1992).

Maquiavelo, Nicolás, "Historia de Florencia", en Obras históricas de Nicolás Maquiavelo, Poseidón, Buenos Aires, 1943.

—, "Dictamen sobre la reforma de la Constitución de Florencia hecho a instancias del Papa León X", en Obras históricas de Nicolás Maquiavelo, Poseidón, Buenos Aires, 1943.

—, El Príncipe, Espasa Calpe, Madrid, 1961.

-, Discursos sobre la primera década de Tito Livio, Alianza Editorial, Madrid, 1996.

MiLleR, Dale, "J. S. Mill's Civic Liberalism": History of Political Thought, vol. XXI, n. ${ }^{\circ} 1$ (2000), pp. 88-113.

MiLl, John Stuart, Collected Works of John Stuart Mill, 33 vols., ed. de J. M. Robson, University of Toronto Press, Toronto, 1977.

-, "Autobiography", en Collected Works, vol. I, Autobiography and Literary Essays.

—, "Thoughts on Poetry and its Varieties", en Collected Works, vol. I, Autobiography and Literary Essays.

-, "The Principles of Political Economy", en Collected Works, vol. II, Principles of Political Economy Part II.

- , "A System of Logic Ratiocinative and Inductive", en Collected Works, vols. VII y VIII.

—, "Sedgwick's Discourse", en Collected Works, vol. X, Essays on Ethics, Religion, and Society.

—, "Bentham", en Collected Works, vol. X, Essays on Ethics, Religion, and Society.

—, "Coleridge", en Collected Works, vol. X, Essays on Ethics, Religion, and Society.

- "To Gustave d'Eichthal" (7 $7^{\text {th }}$ November 1829), en Collected Works, vol. XII, The Earlier Letters of John Stuart Mill 1812-1848 Part I.

-, "To John Sterling" (20 $0^{\text {th }}$ October 1831), en Collected Works, vol. XII, The Earlier Letters of John Stuart Mill 1812-1848 Part I. 
-, "To John Sterling" ( ${ }^{\mathrm{d}}$ October 1839), en Collected Works, vol. XIII, The Earlier Letters of John Stuart Mill 1812-1848 Part II.

-, "To Alexis de Tocqueville" (11 $1^{\text {th }}$ May 1840), en Collected Works, vol. XIII, The Earlier Letters of John Stuart Mill 1812-1848 Part II.

—, "To Auguste Comte" (25 février 1842), en Collected Works, vol. XIII, The Earlier Letters of John Stuart Mill 1812-1848 Part II.

—, "To John Austin" (13 ${ }^{\text {th }}$ April 1847), en Collected Works, vol. XIII, The Earlier Letters of John Stuart Mill 1812-1848 Part II.

-, "To Alexander Bain" (6 ${ }^{\text {th }}$ August 1859), en Collected Works, vol. XV, The Later Letters of John Stuart Mill 1849-1873 Part II.

—, "On Liberty", en Collected Works, vol. XVIII, Essays on Politics and Society Part I.

—, "De Tocqueville on Democracy in America [II]", en Collected Works, vol. XVIII, Essays on Politics and Society Part I.

—, "Recent Writers on Reform", en Collected Works, vol. XIX, Essays on Politics and Society Part II.

—, "Considerations on Representative Government" (1861), en Collected Works of John Stuart Mill, vol. XIX, Essays on Politics and Society Part II.

—, "Taylor's Statesman", en Collected Works, vol. XIX, Essays on Politics and Society Part II.

—, "Guizot's Essays and Lectures on History", Collected Works, vol. XX, Essays on French History and Historians.

-, "Duveyrier's Political Views of French Affairs", en Collected Works, vol. XX, Essays on French History and Historians.

-, "Guizot's Lectures on European Civilization", en Collected Works, vol. XX, Essays on French History and Historians.

-, "The British Constitution", en Collected Works, vol. XXVI, Journals and Debating Spechees Part I.

Pocock, John Greville Agard, El Momento Maquiavélico. El pensamiento florentino y la tradición republicana atlántica, Tecnos, Madrid, 2000.

Pollitzer, María, "John Stuart Mill y el peligro del estancamiento en las sociedades modernas": Estudios Públicos, n. ${ }^{\circ} 128$ (2012), pp. 89-113.

SARALEGUI, Miguel, "Maquiavelo y la partidocracia: tumulto social y mantenimiento de la libertad": Anuario Filosófico, vol. XL, n. ${ }^{\circ} 1$ (2007).

Urbinati, Nadia, Mill on Democracy. From the Athenian Polis to Representative Government, Chicago University Press, Chicago \& London, 2002.

ZAKARAS, Alex, "J. S. Mill, Individuality and Participatory Democracy", en Nadia Urbinati and Alex ZaKaras (eds.), John Stuart Mill's Political Thought. A Bicentennial Reassessment, Cambridge University Press, 2007, pp. 200-220. 